\title{
Effect of Neonatal Hyperbilirubinemia on Ventricular Functions
}

\author{
๑ Birol Karabulut1, ๑ Ayşe Şimşek²
}

1İzmir Katip Çelebi University, Atatürk Training and Research Hospital, Clinic of Pediatrics, Division of Neonatology, İzmir, Turkey

${ }^{2}$ Buca Women and Children Diseases Hospital, Clinic of Pediatric Cardiology, İzmir, Turkey

\begin{abstract}
Objectives: Unconjugated hyperbilirubinemia is a common systemic disease in neonates. Many studies on etiology, risk factors, and treatment have been conducted, and guidelines have been established. Because unconjugated hyperbilirubinemia is a systemic disease, it affects the body, cells, cellular organelles, organs, and systems. Studies have also attempted to clarify the levels, mechanisms, and organs affected by unconjugated bilirubin. We aimed to investigate the effect of high unconjugated bilirubin levels on the left and right ventricular systolic and diastolic functions in newborns by echocardiography and Doppler.
\end{abstract}

\section{Introduction}

Unconjugated hyperbilirubinemia (UCH) is the leading cause of hospitalization and morbidity in neonates ${ }^{(1)}$. Although UCH treatment is well known, the extent of bilirubin damage to the organs and mechanisms
Materials and Methods: This observational retrospective cohort study evaluated neonates with hyperbilirubinemia requiring treatment according to the American Academy of Pediatrics guidelines, who were admitted to our unit between January 2017 and December 2017.

Results: There was no correlation between the serum total bilirubin levels and the echocardiographic measures.

Conclusions: In our study, unconjugated hyperbilirubinemia did not affect the left and right ventricular functions.

Keywords: Neonate, hyperbilirubinemia, cardiac functions

is still being investigated. Many studies show that bilirubin exhibits an antioxidant effect at low levels; causes oxidative stress at high levels and damage on organelles, cells, and organs; and affects the autonomic nervous system ${ }^{(2)}$. However, a great number of these

\footnotetext{
Address for Correspondence: Birol Karabulut, İzmir Katip Çelebi University, Ataturk Training and Research Hospital, Clinic of Pediatrics, Division of Neonatology, İzmir, Turkey

e-mail: dr.birolkarabulut@icloud.com ORCID: orcid.org/0000-0003-0523-153X

Received: 02.08.2019 Accepted: 15.08.2019
}

Cite this article as: Karabulut B, Şimşek A. Effect of Neonatal Hyperbilirubinemia on Ventricular Functions.

EJCM 2019;7(3):142-146.

DOI: 10.32596/ejcm.galenos.2019.08.043

${ }^{\circ}$ Copyright 2019 by Heart and Health Foundation of Turkey (TÜSAV) / E Journal of Cardiovascular Medicine published by Galenos Publishing House. 
studies have mainly focused on the neurotoxicity of the oxidative stress induced by high UCH levels; a few studies have investigated the effects of high bilirubin levels on the circulatory system ${ }^{(3,4)}$. Two in vitro studies performed on the effects of UCH on the myocardial tissue show that UCH damages it, and an in vivo study determines myocardial functional disorder that can be compensated $^{(5,6)}$. A number of studies determine that bilirubin levels increase the tone of parasympathetic nervous system and cause heart rate variability ${ }^{(7,8)}$. To the best of our knowledge, there have been no reports on the high-level UCH effects over the ventricular functions on humans in vivo. Our hypothesis is that $\mathrm{UCH}$ causes oxidative stress, dysautonomia, myocardial injury, and ventricular dysfunction. In the present study, we aimed to investigate the effect of $\mathrm{UCH}$ on ventricular function via transthoracic M-mode and Doppler echocardiographies.

\section{Materials and Methods}

An observational retrospective cohort study was conducted to evaluate neonates who were admitted to our unit with hyperbilirubinemia and who required treatment according to the guidelines of the American Academy of Pediatrics between January 2017 and December $2017^{(1)}$. Our study group included neonates with a gestational age of 37 to 42 weeks according to the Ballard Score or an ultrasound performed before week 20, appropriate for gestational age (AGA), who were admitted for phototherapy, and who had Doppler echocardiography measurements performed due to heart murmur. Exclusion criteria included the age less than 37 weeks or more than 42 weeks, dehydration, electrolytes, acid-base disorders, polycythemia, anemia, neonatal sepsis, being small for gestational age, intrauterine growth restriction, perinatal asphyxia, congenital anomalies, congenital heart defect, chromosome abnormalities, and lack of data. The control group included 20 healthy infants who had Doppler echocardiography measurements performed due to heart murmur. Total, direct, and indirect bilirubin levels were determined through direct spectrophotometry. Gestational age, birth weight, gender, postnatal age, body weight at the time of enrollment, serum total bilirubin, and
Doppler echocardiography measurements were obtained from the patient files.

\section{Echocardiography}

Echocardiography was performed by using a Vivid S6 Ultrasound System (GE Healthcare, Milwaukee, WI) according to the American Society of Echocardiography Guidelines ${ }^{(6)}$. The echocardiographic measurements were performed by a single pediatric cardiologist. Shortening fraction, interventricular septum wall thickness (IVSd), left ventricular end-diastolic (LVED), and left ventricular end-systolic diameters (LVESDs) were obtained by using the M-mode echocardiography by parasternal long axis. Shortening fraction was the difference between the left ventricular end-diastolic and end-systolic diameters; it was calculated by dividing the left ventricular enddiastolic diameter. Left ventricular end-diastolic and end-systolic volumes, and consequently, left ventricular ejection fraction (EF) were measured by the biplane modified Simpson's method.

\section{Tissue Doppler Imaging}

A 2-mm pulse-wave (PW) sample volume was placed on the left ventricular septal mitral annulus, the lateral mitral annulus, and the right ventricular lateral tricuspid annulus at the apical four-chamber abutment. The Nyquist limit was adjusted to the range of -20 to $20 \mathrm{~cm} / \mathrm{s}$, and a high frame rate (>100 frames s-1) was used. During ventricular systole, positive $\mathrm{S}$, which occurs during early diastolic filling negative $\mathrm{E}$ ' and late diastole, left atrial contraction occurs due to the negative wave peak velocities.

\section{Statistical Analysis}

Statistical analyses were performed by using IBM SPSS Statistics Base for Windows, version 22.0 (SPSS Inc., Chicago, IL). The student's t-test for independent and paired samples were used to compare continuous variables. Continuous variables are presented as means \pm SDs, and categorical variables are given as frequencies with percentages. A p value of less than 0.05 was considered statistically significant. 


\section{Results}

During the study period, 247 neonates with hyperbilirubinemia requiring treatment were admitted to our unit. Some of those neonates $(n=43)$ were performed Doppler echocardiography and measurements due to heart murmur. Of those admitted patients, 24 of 43 neonates were excluded from the study. Thus, 19 neonates were admitted with hyperbilirubinemia requiring treatment (group 1), 20 healthy infants who had Doppler echocardiography measurements performed due to heart murmur (group 2), were included in the study (Figure 1). Comparisons of the demographic characteristics between the groups are summarized in Table 1. Serum total bilirubin levels, BIND score, and bilirubin/albumin ratio were significantly higher in the study group. M-mode echocardiography measures are shown in Table 2. There were no significant differences in EF, FS, LVEDd, and LVEDs between the two groups. However, the IVSd was found significantly higher in the study group. We found that there were no significant differences in terms of mitral, tricuspid, septal E', A', and S' between groups (Table 3). Furthermore, we

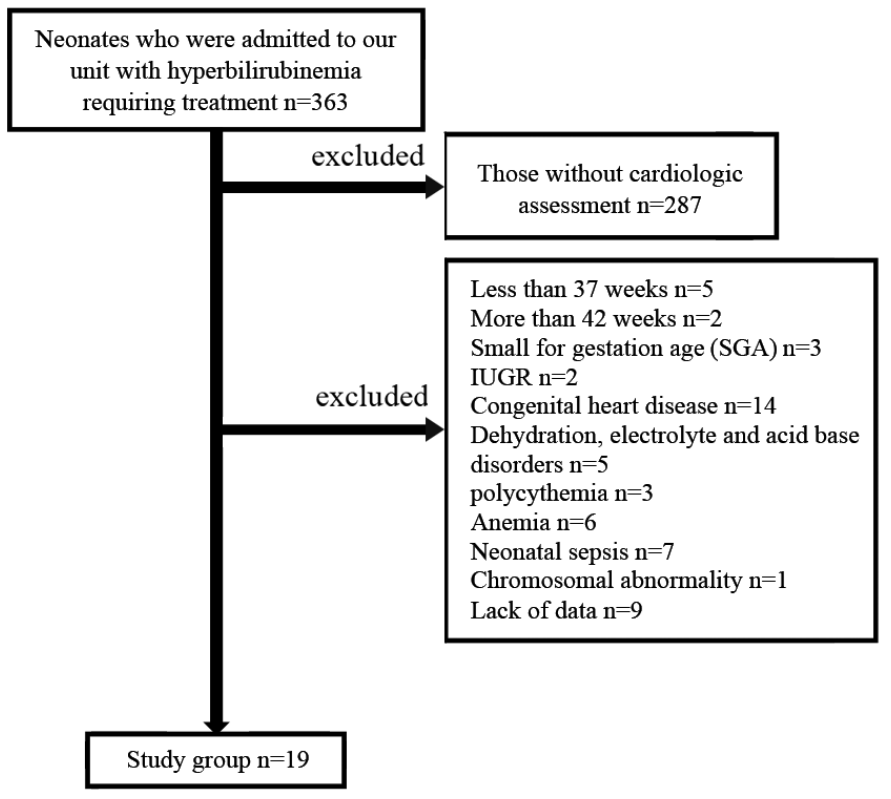

Figure 1. Flowchart of study group

PPROM: Preterm premature rupture of the membranes; IUGR: Intrauterine growth retardation, SGA: Small for gestational age could not find any correlation between the serum total bilirubin levels and echocardiographic measures.

\section{Discussion}

The UCH damage mechanism across organs and systems in neonates is an updated issue that researchers want to investigate. Thus far, studies about the unconjugated bilirubin effects on the central nervous system through the immature blood brain barrier have been conducted ${ }^{(9-11)}$. However, there are very few studies about the UCH effects on the cardiovascular system. Several studies have been conducted on autonomic control and heart rate variability to demonstrate the relationship between the cardiovascular system and hyperbilirubinemia ${ }^{(5)}$. There are also two in vitro studies

Table 1. Demographical characteristics and laboratory signs of the groups

\begin{tabular}{|l|l|l|l|}
\hline Parameters & $\begin{array}{l}\text { Study } \\
\text { group }\end{array}$ & $\begin{array}{l}\text { Control } \\
\text { group }\end{array}$ & $\mathbf{p}$ \\
\hline $\begin{array}{l}\text { Gestational age at admission, } \\
\text { days (mean } \pm \text { SD) }\end{array}$ & $4.3 \pm 1.1$ & $5.1 \pm 1.3$ & $>0.05$ \\
\hline $\begin{array}{l}\text { Male gender (\%) } \\
\text { Gestational age, weeks }\end{array}$ & 63.1 & 55 & $>0.05$ \\
\hline (mean \pm SD) & $39 \pm 1.3$ & $40 \pm 1.7$ & $>0.05$ \\
\hline Birth weight, g (mean \pm SD) & $3218 \pm 336$ & $3296 \pm 341$ & $>0.05$ \\
\hline $\begin{array}{l}\text { Weight at admission, g } \\
\text { (mean } \pm \text { SD) }\end{array}$ & $3186 \pm 304$ & $3212 \pm 316$ & $>0.05$ \\
\hline $\begin{array}{l}\text { Total bilirubin, mg/dl } \\
\text { (mean } \pm \text { SD) }\end{array}$ & $21.7 \pm 4.4$ & $4.5 \pm 0.9$ & $<0.01$ \\
\hline BIND score (mean \pm SD) & $2.1 \pm 0.2$ & 0 & $<0.01$ \\
\hline $\begin{array}{l}\text { Bilirubin/Albumin (mean } \pm \text { SD) } \\
\text { SD: Standard deviation, BIND: Bilirubin-induced neurologic dysfunction }\end{array}$ & $5.3 \pm 1.2$ & $1.3 \pm 0.2$ & $<0.01$ \\
\hline
\end{tabular}

Table 2. Comparison of the echocardiographic measurements between the groups

\begin{tabular}{|l|l|l|l|}
\hline Parameters & Study group & Control group & $\mathbf{p}$ \\
\hline EF (mean \pm SD) & $74.5 \pm 4.05$ & $78.9 \pm 1.3$ & $>0.05$ \\
\hline SF (mean \pm SD) & $44.4 \pm 1.2$ & $45.3 \pm 1.5$ & $>0.05$ \\
\hline LVEDd (mean \pm SD) & $15.2 \pm 0.4$ & $16.2 \pm 0.5$ & $>0.05$ \\
\hline LVEDs (mean \pm SD) & $7.7 \pm 0.3$ & $8.7 \pm 0.3$ & $>0.05$ \\
\hline IVSd (mean \pm SD) & $4.4 \pm 0.2$ & $3.7 \pm 0.2$ & $>0.05$
\end{tabular}

EF: Ejection fraction, SF: Shortening fraction, LVEDd: Left ventricular enddiastolic diameter, LVEDs: Left ventricular end-systolic diameter, IVSd: Interventricular septum wall thickness (IVSd) 
Table 3. Comparison of the Doppler measurements between the groups

\begin{tabular}{|l|l|l|l|}
\hline Parameters & $\begin{array}{l}\text { Study } \\
\text { group }\end{array}$ & $\begin{array}{l}\text { Control } \\
\text { group }\end{array}$ & p \\
\hline Mitral E' (mean \pm SD) & $5.52 \pm 0.46$ & $4.55 \pm 0.39$ & $>0.05$ \\
\hline Mitral A' (mean \pm SD) & $6.52 \pm 0.32$ & $6.5 \pm 0.25$ & $>0.05$ \\
\hline Mitral S' (mean \pm SD) & $4.52 \pm 0.24$ & $4.5 \pm 0.25$ & $>0.05$ \\
\hline Tricuspid E' (mean \pm SD) & $5.63 \pm 0.32$ & $5.1 \pm 0.4$ & $>0.05$ \\
\hline Tricuspid A' (mean \pm SD) & $9.05 \pm 0.49$ & $9.15 \pm 0.59$ & $>0.05$ \\
\hline Tricuspid S' (mean \pm SD) & $5.68 \pm 0.32$ & $6.45 \pm 0.5$ & $>0.05$ \\
\hline Septal E' (mean \pm SD) & $4.31 \pm 0.28$ & $3.8 \pm 0.23$ & $>0.05$ \\
\hline Septal A' (mean \pm SD) & $5.57 \pm 0.33$ & $6.3 \pm 0.44$ & $>0.05$ \\
\hline Septal S' (mean \pm SD) & $3.63 \pm 0.23$ & $3.85 \pm 0.2$ & $>0.05$ \\
\hline SD: Standard deviation & & & \\
\hline
\end{tabular}

investigating the effects of hyperbilirubinemia on myocardial function ${ }^{(12,13)}$. Even the effect of a systemic disease on the cardiac function is always an updated subject of research, no study has been conducted on the clinical cardiovascular effects of hyperbilirubinemia with echocardiography and tissue Doppler. Basu et al. ${ }^{(3)}$ measured the levels of plasma malondialdehyde (MDA), 8-hydroxy-2'-deoxyguanosine (8-OHdG), and total antioxidant status of the neonates. They reported that serum total bilirubin decreased the antioxidant defense effect over $16 \mathrm{mg} / \mathrm{dL}$ and led to lipid peroxidation with values above $20 \mathrm{mg} / \mathrm{dL}$, resulting in DNA damage of all levels of bilirubin levels. Ostrow et al. ${ }^{(9)}$ have concluded that elevated UCH levels are caused by astrocyte and neuronal apoptosis by mitochondrial and plasma membrane damage. In another study, Paludetto et al. ${ }^{(10)}$ evaluated the behavioral score in neonates with hyperbilirubinemia (mean value $=14.3 \mathrm{mg} / \mathrm{dL}$ ). Brazelton developed a newborn behavioral scoring at the $87^{\text {th }}$ and $104^{\text {th }}$ hours and third week. There was a significant difference in behavior between the two groups at the $87^{\text {th }}$ and $104^{\text {th }}$ hours. They arrived at the end of the $3^{\text {rd }}$ week scoring loss of consciousness. The study of Specq et al. ${ }^{(7)}$ included five preterm lambs with hyperbilirubinemia $(150-250 \mu \mathrm{mol} / \mathrm{L})$ and six healthy preterm lambs. They reported a decrease in breathing rate and increased apnea frequency, and they detected that the inhibition of laryngeal and pulmonary chemoreflexes and bradycardia were more common in the preterm lambs with hyperbilirubinemia. Uhrikova et al. ${ }^{(5)}$ found that UCH caused heart rate variability by disrupting autonomic function. In another study performed with 50 cases with high bilirubin level $(20.23 \pm 5.53 \mathrm{mg} / \mathrm{dL})$ and 50 healthy newborns, Özdemir et al. ${ }^{(8)}$ found that the mean minimum heart rate, rMSDD, LF, and LF/HF ratio in the study group were significantly lower due to autonomic dysfunction caused by parasympathetic dominance. Bakrania et al. ${ }^{(12)}$ reported that in an in vitro study on hyperbilirubinemia, myocardial contractility was reduced, whereas in an in vivo study with mice, the ejection fraction and the shortening fraction were the same as in the control group. Gao et al. ${ }^{(13)}$ evaluated CK, CK-MB, Troponin I, and left and right ventricular function via echocardiography in their study of 178 neonates with $\mathrm{UCH}$. They established sufficient evidence that the bilirubin levels caused myocardial damage.

In the present study, we aimed to investigate the effect of bilirubin levels on the right and left ventricular functions through echocardiography. EF and FS could evaluate left ventricular systolic function, the left ventricular systolic functions were the same in both groups, and hyperbilirubinemia did not impair the left ventricular systolic function. The left and right ventricular diastolic functions were evaluated through Doppler echocardiography in both groups considering mitral, tricuspid, septal E', A', S' values. Those measurements were similar in both groups, and hyperbilirubinemia did not impair left and right ventricular diastolic functions.

\section{Conclusions}

We report that hyperbilirubinemia does not impair the left and right ventricular function. Therefore, exposure time and severity level of $\mathrm{UCH}$ are also as effective as the degree of hyperbilirubinemia in affecting myocardial functions. We conclude that new studies with more severe UCH and larger sample sizes need to be conducted. 


\section{Ethics}

Ethics Committee Approval: Retrospective study.

Informed Consent: Retrospective study.

Peer-review: Externally and internally peer-reviewed.

\section{Authorship Contributions}

Surgical and Medical Practices: B.K., A.Ş., Concept: B.K., Design: B.K., Data Collection or Processing: B.K., Analysis or Interpretation: B.K., Literature Search: B.K., Writing: B.K.

Conflict of Interest: No conflict of interest was declared by the authors.

Financial Disclosure: The authors declared that this study received no financial support.

\section{References}

1. American Academy of Pediatrics: Management of hyperbilirubinemia in newborn infants 35 or more week of gestation. Pediatrics 2004;114:297316

2. Lang RM, Bierig M, Devereux RB, et al. Recommendations for chamber quantification: a report from the American Society of Echocardiography's Guidelines and Standards Committee and the Chamber Quantification Writing Group, developed in conjunction with the European Association of Echocardiography, a branch of the European Society of Cardiology. J Am Soc Echocardiogr 2005;18:1440-63.

3. Basu S, De D, Khanna H, Kumar A. Lipid peroxidation, DNA damage and total antioxidant status in neonatal hyperbilirubinemia. Journal of Perinatology 2014;34:519-23.
4. Kaplan M, Bromiker R, Hammerman C. Severe neonatal hyperbilirubinemia and kernicterus: are these still problems in the third millennium? Neonatology 2011;100:354-62.

5. Uhrikova Z, Zibolen M, Javorka K, Chladekova L,Javorka M. Hyperbilirubinemia and phototherapy in newborns: Effects on cardiac autonomic control. Early Human Development 2015;351-6.

6. Bhavisha B, Eugene F, Toit D, et al. Hyperbilirubinemia modulates myocardial function, aortic ejection, and ischemic stress resistance in the Gunn rat. Am J Physiol Heart Circ Physiol 2014;307:H1142-9.

7. Specq ML, Bourgoin-Heck M, Samson N, Corbin F, Gestreau C, Richer M, et al. Moderate Hyperbilirubinemia Alters Neonatal Cardiorespiratory Control and Induces Inflammation in the Nucleus Tractus Solitarius. Front Physiol 2016;30;7:437.

8. Özdemir R, Olukman Ö, Karadeniz C, et al. Effect of unconjugated hyperbilirubinemia on neonatal autonomic functions: evaluation by heart rate variability, Journal of Fetal Maternal and Neonatal Medicine 2017;31:2763-9.

9. Ostrow JD, Pascolo L, Brites D, Tiribelli C. Molecular basis of bilirubin induced neurotoxicity. Trends Mol Med 2004;10:65-70.

10. Paludetto R, Mansi G, Raimondi F, et al. Moderate hyperbilirubinemia induces a transient alteration of neonatal behavior. Pediatrics 2002;110:e50.

11. Watchko JF. Neonatal indirect hyperbilirubinemia and kernicterus. In: Gleason CA, Devaskar SU (eds). Avery's diseases of the newborn. 9th ed. Philadelphia, Elsevier Saunders; 2012. p. 1123-43.

12. Bakrania B, Toit EF, Ashton KJ, et al. Hyperbilirubinemia modulates myocardial function, aortic ejection, and ischemic stress resistance in the Gunn rat. Am J Physiol Heart Circ Physiol 2014;307:H1142-9.

13. Gao XY, Yang B, Hei MY, et al. Clinical study of myocardial damage induced by neonatal jaundice in normal birth weight term infants. Zhonghua Er Ke Za Zhi 2012;50:343-9. 